youngest being 1 year 9 months, with a mortality of only 3.2 per cent., and there was only 1 case of recurrence out of the number. The average weight of calculi removed was just under 90 grains. The four deaths were all due to organic disease of the kidneys.

In Girls lithotrity should be the rule, but, if impracticable, then suprapubic lithotomy.

In Adult Females.-For small stones, lithotrity or litholapaxy, or dilatation and removal ; for large stones, suprapubic lithotomy.

In Male Adults.-Lithotrity for all small stones, and even for large ones, which can be seized and crushed with Thompson's largest improved Bigelow lithotrite; otherwise the suprapubic operation. Lithotrity is not applicable to cases of encysted stone, nor to some cases in which the bladder is much contracted. Stricture should not militate against lithotrity, as internal urethrotomy should be performed as a preliminary.

In Old Men (for example, those over 65) lithotrity should also be the rule, failing which, if there be no considerable enlargement of the prostate, median cystotomy, combined with crushing; if much prostatic hypertrophy exist, the high operation for stone (although much risk is involved in all over 70) is yet, I venture to think, more likely to be successful than lateral lithotomy.

Table showing particulars of Forty Consecutive Cases of Lithotrity or Litholapaxy. All the Patients were Males except Nos. 1 and

40. $R=$ recovery,$D=$ death .

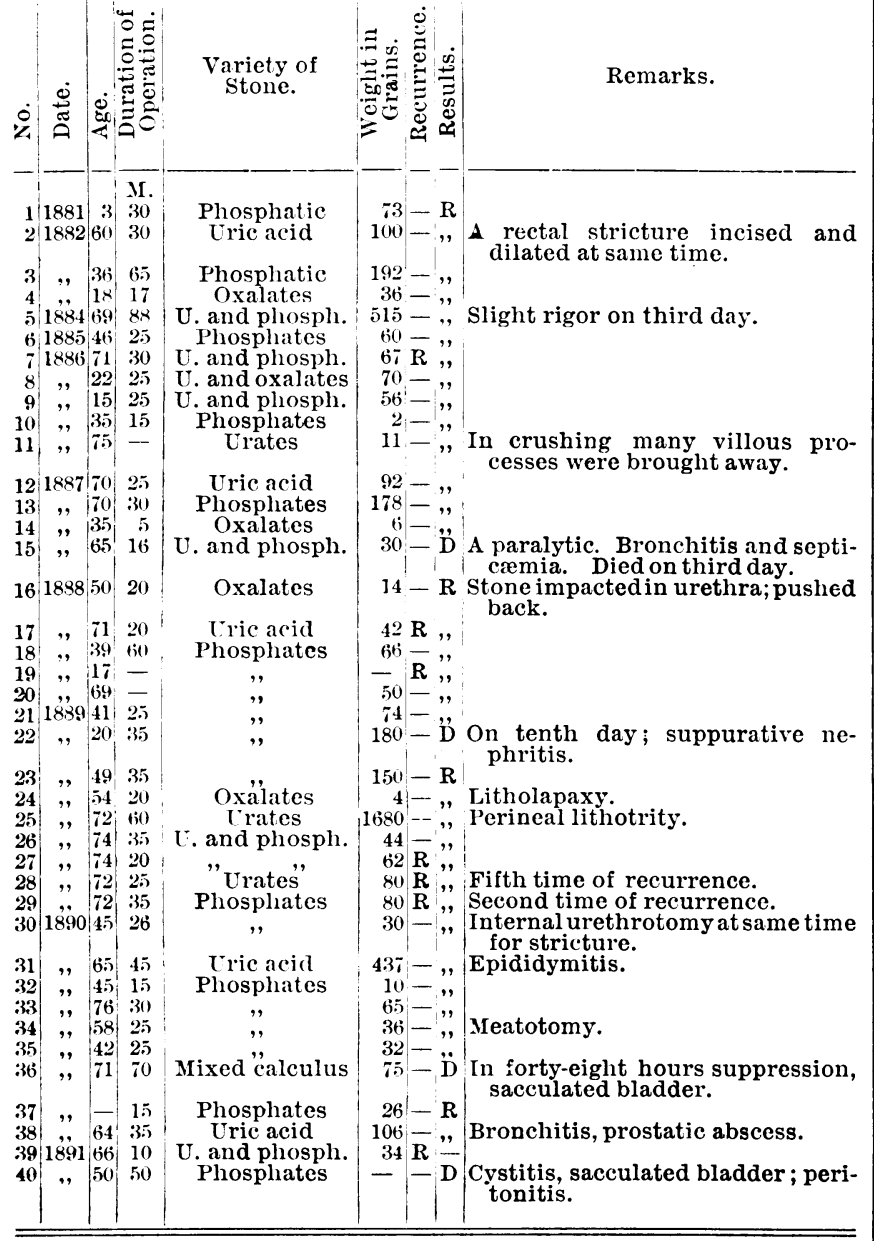

Fatal Football.-Thomas G. Meadowcroft, aged 21, has met his death from injuries incurred in a football match played at Newbey.

\section{CASE OF ELEPHANTIASIS ARABUM.}

By C. E. ABBOTT, L.R.C.P.I., M.R.C.S.

THE case is a well marked example of an affection rare in this country. Dr. Duhring, Philadelphia, in his work on Diseases of the Skin, 3rd edition, 1882, writes as follows:

"Elephantiasis Arabum is a chronic hypertrophic disease of the skin and subcutaneous connective tissue, characterised by enlargement and deformity of the part affected, accompanied by lymphangitis, swelling, cedema, thickening, induration, pigmentation, and papillary growth. Elephantiasis

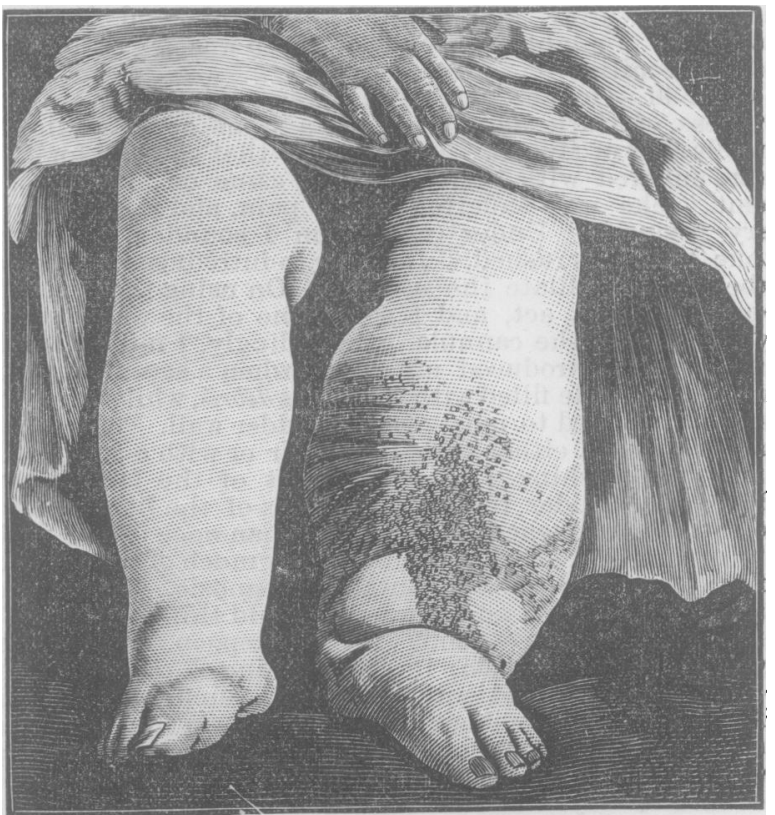

Græcorum, or true leprosy, is an endemic, chronic, malignant, constitutional disease, characterised by alterations in the cutaneous, nerve, and bone structures, resulting in anæsthesia, ulceration, necrosis, general atrophy, and deformity." The dark races are more liable to elephantiasis than the fair. In India it is particularly liable to attack the scrotum; in the West Indies the leg is its favourite seat, hence the term "Barbadoes leg."

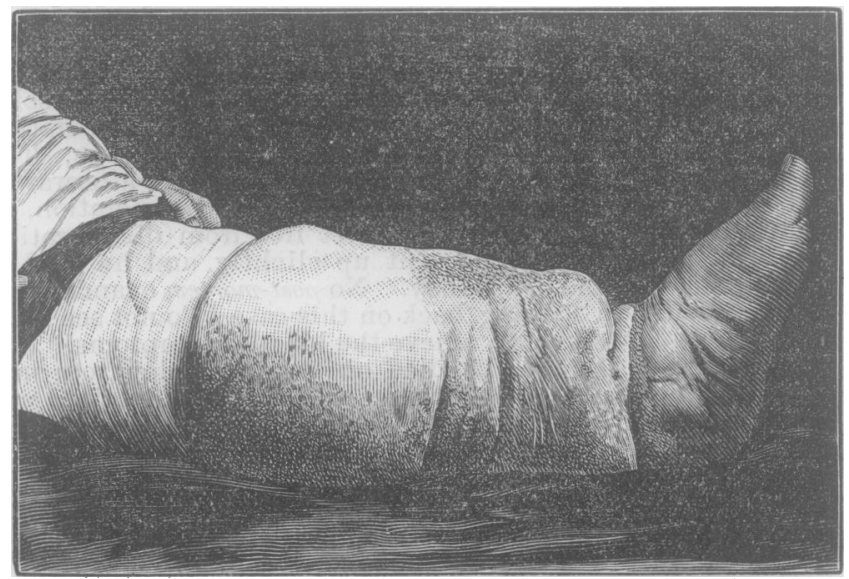

The patient is a widow, aged 62 . She has a florid complexion, and is not a "drinker." She complains chiefly of difficulty in walking, caused by the disease which affects her left leg. She is very fat, weight 16 stone, height $4 \mathrm{ft}$. 11 in. The patient was thin up to the age of 43 , when, after the 1 Read before the Essex.District, East Anglian Branch. Case exhibited. 
birth of her last child, she began to grow stout. She has been under my observation for the last twelve years, during which time the disease in the leg has developed, and steadily increased. When first seen in 1879 the left leg was slightly larger than the right, but there existed at that time no indication of the elephantiasis. The patient states she had white swelling of the leg affected after her tenth confinement twentythree years ago; she was confined to the house for three months from this cause. What relation there was between this illness and the present condition I am not prepared to state; the interval between the confinement referred to and the onset of the present condition, about twelve years, does not favour the connection. The present condition began with slight constitutional disturbance; enlargement of the foot and leg became general; some patches of eczema were troublesome for several years, the leg gradually taking on the appearance it now presents. This is well shown in the accompanying illustration.

The following are the dimensions of the legs in circumference :

4 inches below knee, sound leg, 16 inches ; left leg, 27 inches

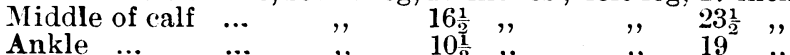

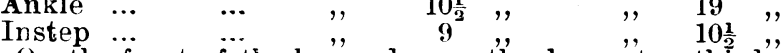

On the front of the leg' and over the lower "two-third"s the skin presents a tuberculated, horny, and pigmented appearance. Just below the popliteal space a deep sulcus extends about two-thirds round the leg; several other depressions are to be seen lower down, more particularly on the inner side. The ankle is well worthy of attention, the hypertrophied leg overhanging the foot, and appearing even larger than it is from the depression in front of the ankles; the dorsum of the foot is also much hypertrophied, and on this surface are several areas of congested skin from varicose veins. The outer side of the leg is much infiltrated.

Digestive system normal. Nervous system: has headache and neuralgia at times. Patellar reflex absent. Respiratory system normal except shortness of breath on exertion; this is no doubt due to obesity. Circulatory system: heart sounds clear: there is probably some fatty degeneration of the heart, and no doubt the arteries of the affected limb are enlarged. 'Trine, clear acid, specific gravity 1016; no albumen.

Treatment. - The patient refuses operative measures. An elastic bandage is at times worn.

\section{HYDATID OF LIVER: ABDOMINAL SECTION, INCISION, AND DRAINAGE.}

BY THOMAS EASTES, M.D.Lond., F.R.C.S., Folkestone.

E. P., aged 56, widow, was first seen by me in June, 1889 , for an abdominal tumour about the size of two closed fists. It was almost median, chiefly below the umbilieus, only slightly movable from side to side, felt globular, and seemed to extend deeply towards the spine. It could not be connected clearly with any of the viscera, and seemed to be surrounded by a zone of resonance, but was itself dull. It continually increased until September 24 th, 1889 , when an exploratory incision was made, and, after pressing aside liver, bowel, and omentum. a small piece of hydatid cyst wall was uncovered, the cyst was aspirated, and a pint and a quarter of clear hydatid fluid was drawn off. The cyst wall was then incised, sewn to the edges of the peritoneum, and a glass drain introluced. A few small vesicles came out with the fluid. Sixteen days after the operation about two square feet of hydatid membrane were washed out by syringing. Drainage was stopped about six weeks after the operation, and the patient made a perfect recovery. The treatment of living hydatid cysts is as yet far from perfect. Some are cured by being aspirated, only a small portion of the contents needing removal, but some refill, and some suppurate after aspiration.

Incision and emptying the cyst seem the most satisfactory treatment, but I can only find one case recorded where the cyst was closed again at the operation instead of being drained. and that was a case of Mr. Knowsley Thornton's, T where the cavity was sponged out with tincture of iodine, and closed with the same sutures as the abdominal incision. Dr. Verco, of North Adelaide, has recommended removing the whole of the membranes at the same operation; another writer deprecates that, and apparently with good reason, as being liable to cause uncontrollable hæmorrhage, referring to a case of Dr. Bright's, in which the cyst ruptured through the abcominal wall spontaneously, and some of the membranes were removed on the second day after rupture; but next day some more presenting at the aperture resisted removal, and hæmorrhage into the cyst from a hepatic vein commenced and was fatal within thirty-six hours.

It is certain, from the one case already mentioned, that if the cyst be in the abdominal cavity, and the wall fairly thin, and not too rigid so that the general abdominal tension will close it, the cavity may be cleansed by an antiseptic and then closed; but I would suggest that it should simply be sponged out very gently, or, if in a suitable position, be first washed out with clean warm water as the peritoneal cavity is treated, and then gently sponged dry and closed without being drained taking the precaution to keep the opening of the cyst and that of the abdominal cavity in close apposition by closing both with the same sutures in case of possible suppuration, until further experience has shown that to be unnecessary. Even if suppuration supervened, a drainage tube could then be easily inserted; and, if it did not, several weeks of drainage would be saved, three weeks being apparently the shortest time required hitherto, and as many months not being sufficient in protracted cases.

\section{A CASE OF TRAUMATIC CEREBRAL ABSCESS TREPHINING : FREE DISCHARGE OF CEREBRO-SPINAL FLUID : RECOVERY.}

By F. A. SOLTHAM, M.B.Oxon., F.R.C.S., Surgeon to the Manchester Royal Infirmary.

ON June 8th, 1890, Dr. Watson, of Ardwick, asked me to sec in consultation a boy, aged 13 , who, six days previously, while at play, had struck his forehead against the end of a sharp bolt projecting from a door, a slight wound bring produced about two inches above the orbit on the left side. IIe walked home after the accident, which was not considered serious, as it was not followed by any symptoms for several days, except that it was noticed that he was musually dull and heavy. On the morning of the sixth day, when he was first seen by Dr. Watson, his temperature was $101.5^{\circ}$; he was somewhat drowsy, and there was a slight discharge of pus from the wound. The same evening when I examined him, the temperature had fallen to $100^{\circ}$, the pulse was 60 , intermitting every four or five beats; he was quite conscious, speech was perfect, and there were no brain srmptoms. (In exploring the wound with a probe, it passed through a small opening in the frontal bone into the cavity of the cranium; on withdrawing the probe, a few drops of pus oozed from the wound, evidently coming from the interior of the skull it was clear that there had been a punctured fracture of the frontal bone, followed by intracranial suppuration, it was resolved to trephine at the seat of injury.

The operation was performed early the following morning. After raising a semicircular skin flap and removing a circle of bone at the site of fracture, along with nunerous fragments of the inner table, which was extensively splintered, there was a free discharge of pus through a laceration in the dura mater. On introducing the finger through the trephine opening, it passed into a large irregular cavity in the frontal lobe. This was syringed out with boric acid lotion, a quantity of broken down brain substance coming away. A drain. age tube was left in the wound, its end reaching well into the abscess cavity. For the first four days after the operation there was a profuse discharge of pus from the wound, which was syringed out daily with boric lotion. On the morning of the fifth day, it was found that during the night the dressings and pillow on which the boy lay had become saturated with a clear watery fluid. This continued to discharge very freely

2 Bright. "Abdominal Tumours." New Sydenham Society, p. 51 . 